\title{
Anatomical Measurements of the Cartilage, The Size of the Neural tube Of The Lumbar Vertebrae And Its Relationship To The Lower Back Pain *Dr/ Ahmed Abu Elabas Abd Elhamid
}

Introduction and problem of the research:

There is no doubt that the science of injuries and anatomy is one of the important parts of the field of modern sports medicine which had developed by rapid diagnosis and became one of the basic sciences to keep up with the sports movement, and that the study of lumbar area of the vertebral column establishes a new scientific and practical method in the field of anatomy of the vertebral column, which is a gateway to know the diagnosis, study, and treatment. The backbone of human is considered the central axis of the body, which consists of a number of irregular shape and different size vertebrae linked to each other and are separated by intervertebral discs which give them flexibility in movement so that the human can move easily.

Mohammed Qadri Bakri and Siham Elsayed Al-Ghamri (2005) note that the lumbar region represents weak points and problems of mobility for athletes and non-athletes. Due to the vitality of these areas, as it exposes to heavy weight, natural flections and the occurrence of motor work to it more than the other areas, it exhibits to many problems and injuries to athletes and others during the exercise and sports activities or to some other jobs, or wrong sit down while writing or misuse of modern technological devices(141: 14).

Lower back pain is the pain the patient feels in the back, and it is usually due to muscles, nerves, bones or joints of the vertebral column. it can occur surprisingly, quickly or gradually, and can also be continuously or intermittently. The type of pain varies by injury Which takes place and requires understanding the details of lower back pain to identify the

* Lecturer in Anatomy Department of Sports Health Sciences Mansoura University 
basics of nervous system work and pain mechanics in the lumbar region which depends on the understanding of information related to descriptive and functional anatomy of the lumbar region of the vertebral column (12:16).

Mohamed Adel Rushdi, Mohamed Jabir Barka (1997), pointed out that the study of neurological, mechanical and anatomical principles that control in low back pain is one of the most important areas of Functional dysfunction study. The focus is usually on the anatomical and functional aspects of the functioning of the nervous system in the evaluation of low back cases in order to measure the degree of pain, and that most rehabilitation strategies work in the direction of individual perception of pain and focus on the motor side of the nervous system, but both sides must be in rehabilitation especially those related to neuronal nutrition of tissues of this area and the participation of the components of the nervous system to control its movement and to show the extent of integration of the work (12: 55-
$60)$.

Ashraf Mohammed Helmy (2010) clarifies that In order for the movement to occur in a consistent manner, the information obtained from the central nervous system through the sensory centers allows the occurrence of the harmonic acts between the work of the motor control centers and the different muscles. The lower back pain directly affects the natural balance in the work of both Sensory nerves and motor nerves (4: 15-16).

Mohammad Kadri Bakri and Ali Mohammed Jalaluddin (2011) agree that the anatomical structure of the lumbar vertebrae is characterized by the difference in shape and size according to its location in the vertebral column. The lumbar vertebral column is also called the abdominal vertebrae because it is located in the abdomen and they are distinguished by their huge shape. On the other hand, the spinal canal is small triangular, the back vertebral column is large, strong, wide and unbroken, and the diapophysis is short, wide and has no arthriticus surfaces 
(251:15).

Java Script and Openi (2000) confirm that the area of the lumbar is larger than the other areas where the burden lies in either normal standing or prolonged sitting, and beyond that the violent and abrupt movements which athlete do while exercising. The lumbar region of the vertebral column has a complex structure as it connects or reaches the upper part with the lower part of the body and thus increases the strength and ability of the individual to work. It also allows the body to move while twisting on the sides or curving and bending forward. The strength of this part of the vertebral column enables, the human to stand up, walk, raise objects, perform athletic skills and daily activities, and low back pain can affect the activity of the individual, reduce the ability to perform sports exercises, and not achieving the digital level of weight lifting - wrestling players (23: 1-2).

Al-Azab (2005) points out that the injury of the lumbar vertebrae is one of the most common injuries to the vertebral column where its cartilage exposes to a great deal of stress and that the pain in this area has become a problem for many individuals and athletes that may affect the fulfillment of their required duties $(6: 3)$.

Yusuf

Lazem

Kamash and Saleh Bashir Saad (2011) note that the anatomical structure of vertebral cartilage is a connective tissue with a solid nodular material. The cartilage has a smooth, flexible surface that helps the movement of the bone to be easily. This tissue contains singular or in groups cartilage cells, and these cells form the fiber and the nodular material. It also contains the cartilage and collagen fibers or elastic fibers. The nodular material in the cartilage is composed of mucopolysaccharide and proteins. The cartilaginous tissue includes three types:

Hyaline Cartilage: It is a homogeneous tissue with a white color that tends to blue and contains cartilage cells which are formed in small groups and surrounded by perichondrium. This cartilage is the most common cartilage in the body as it forms the 
skeleton of the fetus. It is also in the joints and is a part of the formation of the larynx, trachea and bronchi.

Fibrous Cartilage: It is composed of a dense mass of white fibers that are immersed in the solid nodular material. This cartilage is rich in collagen fibers. It is also strong and has limited elasticity and is found in the vertebral discs, the knee joint and the pubic symphysis.

Elastic Cartilage consists of elastic fibers immersed in a solid material. The cells are located between the yellow fibers and are surrounded by perichondrium. It is found in the earlap and the Epiglottis. This flexible cartilage is more rigid than the hyaline cartilage and more elastic than the fibrous cartilage (19: 42-43).

Plastanga et al. (1998) note that cartilage discs in the vertebral column is $25 \%$ of the length of the vertebral column in adults and $40 \%$ in children. The vertebrae are separated by cartilage disks which are thicker as we move down, in cervical vertebrae $(5 \mathrm{~cm})$, in thoracic vertebrae $(7 \mathrm{~cm})$ and in the lumbar vertebrae (10 $\mathrm{cm})$. The cartilage is composed of two parts: the annulus fibrosus and the pulpy nucleus. The highest cartilage found between the second and third cervical vertebrae and the lowest cartilage disc in the coccygeal area. Its primary function is to absorb impacts and it consists of the vertebral plate, the annulus fibrosus, and the pulpy nucleus (27: 634).

Parallel fibers in the form of a spliced segment (12: 20) slice, containing cartilage cells and nerve endings in half of the outer lyar and leading to markers of the pain receptors, its thickness ranges between 200: 400 microns. Each part of this fiber contains a small fiber bundle which varies in thickness between 50:10 microns. Mechanical pressure due to vertebral column movement in adults is responsible for arranging these fibers in parallel.

As the age progresses, this area becomes weak and can be opened and the nucleus can be appeared. The white nucleus is a part of the center of the cartilage, and it is a very delicate gelatinous material which is very sensitive to the mechanical and chemical effect which is responsible of 
the cartilage growth process and its size during growth.

In light of the above, after reading many references, research and scientific studies, through the international information network, through the experience of the researcher, a study of descriptive and functional anatomy, and his work in the field of injuries and rehabilitation note that some athletes suffer from low back pain due to movement or violent effort may exist pain In the resting position due to lack of adequate warm-up, especially when performing exercises or the use of heavy weights beyond the limits of strength of the muscle which are surrounding the lumbar region, the study of this area gives us a new scientific and practical basis to follow the effects of a practitioner sports activities.

Due to the nature of sports activities, the different methods of performance, the quality of the medium in which the activity is done, the difference in muscular and nervous work on the vertebral column, and also the difference in training periods, some factors may occur and may affect the level of performance, including anatomical change in the form of lumbar region, which may lead to lower back pain and may be a problem in the future. This study was designed to identify the anatomical measurements of cartilage, the size of the neural tube of the lumbar vertebral column and its relation to lower back pain.

\section{Research Objective:}

This research aims to identify the anatomical measurements of cartilage, the size of the neural tube of the lumbar vertebrae and its relation to lower back pain by identifying the following:

The size of the neural tube in the research sample.

Cartilage discs in the lumbar region in the research sample.

The relationship of anatomical measurements of cartilage and the size of the neural tube with lower back pain.

\section{Research Questions:}

What are the anatomical measurements of the size of the neural tube in the research sample?

What are the anatomical 
measurements of the cartilage of the lumbar region in the research sample?

Is there a relationship between anatomical measurements of cartilage, neural tube size, and lower back pain?

\section{Research Terms:}

Anatomical measurements:

The study of the anatomical measurements of the human body, which is the measurements of the bones, muscles and the changes that occur in them (Procedural definition).

\section{Neural tube:}

Elnawasra

(2007)

said that it is the cavity which is located in the vertebrae and through it the spinal cord and its membranes pass as well as cerebrospinal fluid C.S.F and blood vessels of the spinal cord (7: 85).

\section{Related studies:}

The study of Ashraf Eldusoki Sha'alan and Magdy Mahmoud (1999) under the title "A Rehabilitation Program For The Relief Of Lower Back Pain In The Lumbar Region Resulting From Cartilage Slide". The study aims at designing a proposed exercise program for the rehabilitation of lower back pain caused by cartilaginous glands in the lumbar region. To identify the effect of the proposed exercise program for the rehabilitation of lower back pain resulting from glacial discoloration in the lumbar region in the variables under study, a comparison is conducted between two groups (Control Experimental). In the variables under study, the study sample was randomly selected by 12 patients with a slipped disc in the lumbar area represented by the experimental group and the other 12 individuals. The researcher used the experimental method and the results of the study were that the application of the rehabilitation program leads to relief of lower back pain and helps in developing the functional efficiency of the vertebral column.

The study of Marwa Farouk Ghazi (2011) (17): "The title of the study is" a study to develop some anatomical and physical variables for the practitioners of some sports activities". This study aims to identify the effect of different sports on some anatomical and physical 
variables. The survey method was used to suit the nature of the research. The sample of the research was selected in a deliberate manner from the various sports players (swimming, gymnastics, weight lifting), 36 players divided into (9) for each sport and the results showed that there is an inclusion of results for anthropometric measurements naturally according to the stages of the ages for beginners and advanced levels.

Study of Ahmad Fikry Al-Mughni (2008) (1): "The title of the study is "a rehabilitation program for vertebral column efficiency in cases of lower back pain". The aim of this study is to identify the effect of the rehabilitation program for vertebral column efficiency in cases of lower back pain. The sample of the research was selected in a deliberate manner of the men with lower back pain who was (8) men and the researcher used the experimental method. The results showed that there was a statistical improvement of the experimental group in both pain measurement measuring the strength of the abdominal and back muscles, elasticity of the vertebral column in all directions, and elasticity of the lumbar region.

Study of El-Sayed (2009) (2): "Title of the study "the effect of the practice of synchronized swimming on the corners of the vertebral column". The purpose of this study is to identify the effect of practicing the swimming of the signature on the corners of the vertebral column of different stages of the years. The researcher used the descriptive approach. The sample of research were chosen by the deliberate way of the swimming players of the clubs (Elzhour - El Ahly - Heliopolis - Elshams) who are players in the Egyptian Swimming Federation in (2007). The sample contained 55 players and the most important results record of the group's cervical test practice value of $(0.81)$, exercise value of (0.73) in favor of $m(0.77)$ and the nonexercise group (1.04) for the swimmers. The lumbar projection of the group was recorded at a value of (3.75) and the non-exercise group value of (3), 19) for the practice of synchronized swimmers and a record of the cervical angle of the group practice value of $(6,31)$ and the non-practicing group value of (8.02) for the practice of 
swimmers signature.

The study of Mohammed Elsayed Abd Elaziz (2004) (13) under the title " Directions of the cartilaginous nucleus sliding in the lumbar area and its relation to the followed rehabilitation programs". It aims to identify the relationship of the directions of the cartilaginous nucleus sliding in the area and the rehabilitation programs that are used to determine the common directions of the cartilaginous nucleus sliding in the lumbar area. The researcher used the descriptive method on a sample of (15) infected with the cartilaginous nucleus sliding of men aged (30-45) years. They were divided into three equal groups and each group was treated by different rehabilitation program. The results of the study revealed that the injury of the cartilaginous nucleus sliding in the lumbar area has different effects on the motor range, strength of the muscles working on the trunk, and lower limb according to the sliding directions (front, rear, side). The rehabilitation programs differ according to the different treatment institutions, and not to the difference in the direction of sliding of the cartilage nucleus. The rehabilitation program in the first group was successful, as it suits with the direction of the cartilaginous nucleus sliding more than the second and third groups in terms of improvement of muscle strength and functional test.

\section{The study of Amonoo-} Kuifi (1990): "Title of study: "Morphological changes in the dimensions of cartilage between lumbar vertebrae through age." This study aims to identify the changes that occur to the cartilage dimensions such as the internal and external length of the age of (10 -64). A general study was conducted on a sample of (305) individuals using $\mathrm{x}$-ray and then measuring dimensions to the nearest millimeter. The study concluded that there are significant differences in the dimensions of cartilage in all age groups, but in different proportions until the second decade of age -most likely- at the completion of puberty and then contract until the fourth decade of age is about $2 \mathrm{~mm}$ and then the decline occurs clearly from the fifth decade of life.

Study of Stacos et al. (2006) (29): "Study Title: Growth of the body of vertebrae and cartilage in height in adolescents" This study aims at finding the relationship between the growth of the vertebrae and cartilage (the length of the vertebral column between T5 and L5). A sample of (188) of 
age (7.5:20) was studied. The study showed that the length of the vertebral column (250: 350 $\mathrm{mm}$ ) increased during the phase and this corresponds to the increase in the length of the body of the vertebrae after the age of 10 years until the stabilization of the increase after the age of 12 years.

The study of Roush et al. (2008) (28): "The title of the study: Changes in the length of the vertebral column at different distances during walking (3 miles)" This study aims to identify changes in the length of the vertebral column during each half mile. The study was conducted on a sample of 20 men and 20 women aged 21: 40 years. The study was conducted using a walkway and a standard tape to measure the length of the vertebral column (from C7S2). There are differences in the length of the vertebral column between $(0.5: 1)$ miles and between (1: 1.5) miles and so that the length of the vertebral column decreases as the walking distance increased.

The study of White and Malone (1999) (30): "Title of the study "The effect of running on the height of the cartilage of the vertebral column" This study aims to find the relationship between long run and the increase in the rate of loss in the height of the cartilage of the vertebral column in the form of a decrease in the total length of the vertebral column. The study was conducted on a sample of (30) active players aged (17: 29) years using the flexible tape to measure the vertebral column of $\mathrm{C} 7$ (S1) three times in order to reach the average measurement limit and the study ended to have significant differences between the height of the cartilage before and after running.

The study of Luiz hemerique, et al. (2006) (26). The title of the study is "A study of the lumbar concavity angles values. It aims to identify the role of vertebrae and cartilage and its effect on the angles the lumbar concavity. X-rays were done for 350 individuals (18: 50) years, the lumbar and sacral lumbar angles were measured. This study resulted in the determination of less than (61) degrees of angular lumbar spine and a length of less than $\left(45^{\circ}\right)$ for lumbar.

Study of Baranto et al. (2009) (21): The title of the study is "A study of dorsal and lumbar vertebral column changes for professional athletes in four different sports." Follow-up study for 15 years. This study aims to conduct a longitudinal study on the vertebral column to determine changes in the dorsal and lumbar areas. The study 
was conducted on a sample of (71) professional athletes from weight lifting, ice hockey, wrestling and gymnastics, and (21) non-sports practitioners. The study was conducted by magnetic resonance imaging and clarified that there is a reduction in cartilage $(90 \%)$ of the sample athletes, especially in weight lifting players and then gymnasts.

Through previous studies, the researcher extracted the following:

He benefits from the results of the previous studies in determining the steps which he shall follow in the research procedures.

Provide devices and tools that help to know developments in the body, especially during the implementation of anatomical measurements.

Assist the researcher in conducting anatomical measurements that help in the collection of data.

Selection of sample, methodology and tools of data collection used in measurement.

Determine the appropriate method to view, analyze and interpret data.

Choose the appropriate statistical method.

Research Methodology:

The researcher used the descriptive approach to suit the nature of the research and to achieve the research objectives and questions.

\section{The Research Sample:}

The sample of the research was deliberately selected from the athletes who suffer from lower back pain in the following s (weight lifting wrestling). The sample included (10) players, ranging in age (22:18) years.

\section{Conditions for Sample Selection:}

1 - Selection of the sample of the research from the players of sports activities (weight lifting - wrestling).

2- Volunteering in the experiment throughout the study period.

3 - Selection of the sample of the research from the players of sports activities (weight lifting - wrestling) suffering from lower back pain.

4. All members of the sample shall be male.

5- The research sample should have the desire to participate.

\section{Distribution of the research sample:}

The search sample modality was performed in the underlying variables 
.Table (1)

The moderation of the research sample in the basic and physical variables under consideration $(\mathbf{N}=10)$

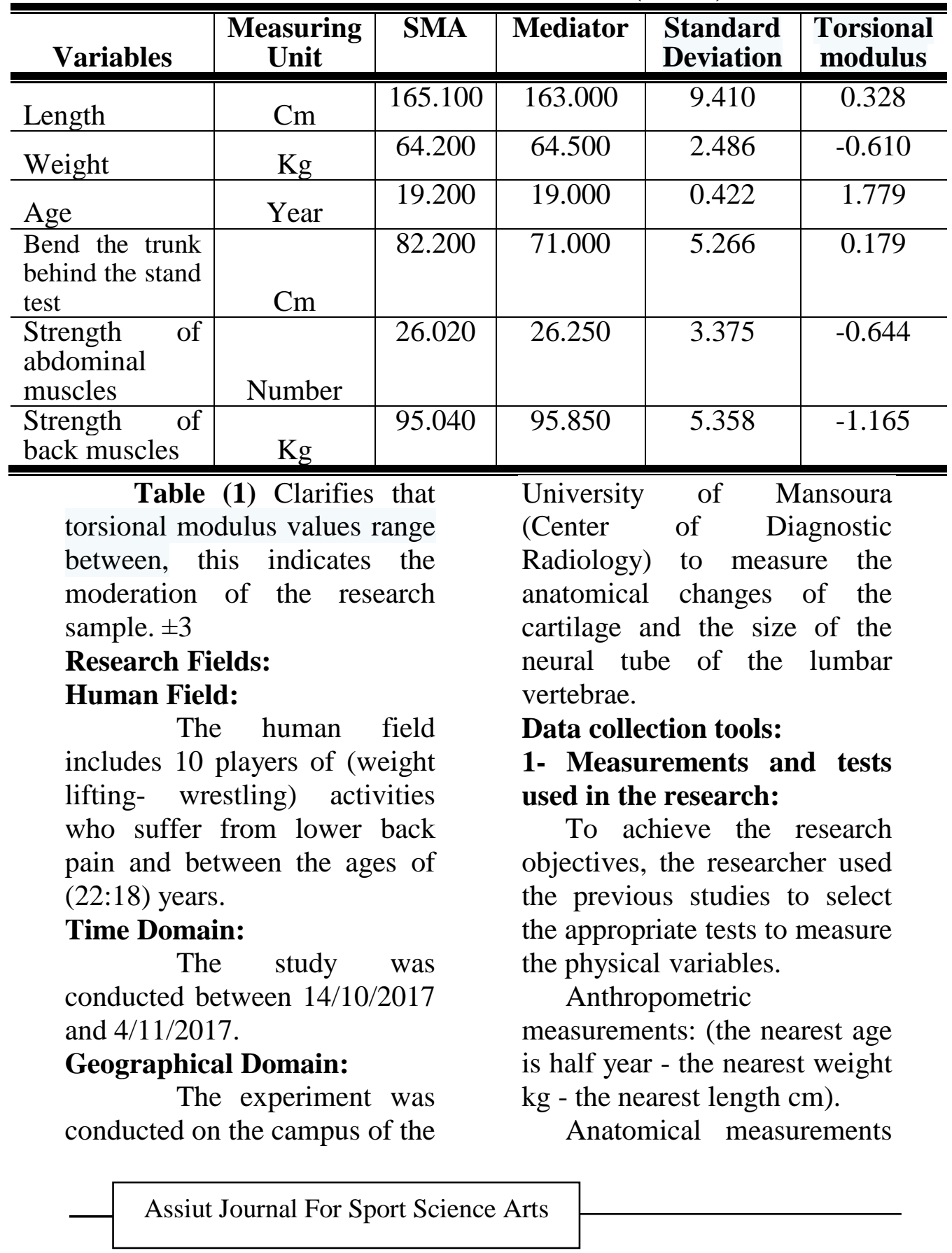


of the lumbar area:

Anatomical measurements of the size of the neural tube of the lumbar region.

The degree of pain.

Anatomical measurements of the cartilage of the vertebrae.

\section{Physical Tests:}

Bend the trunk behind the stand test

Strength of abdominal muscles

Strength of back muscles

2- Research Devices and Tools:

The researcher used the following tools and devices conduct research

measurements:

-Resistometer for measurement of length (cm).

- Medical scale to measure weight $(\mathrm{kg})$.

- Data registration forms.

- Computer to measure of radiation (film) of the player.

- X-ray device equipped with specific and agreed factors to standardize the measurement.

- X-ray program.

- The degree of pain sensation.

- Visual symmetry test to measure the intensity and degree of pain.

Exploratory Study:

The researcher conducted an exploratory study on a sample of (4) athletes who suffer from of lower back pain outside the basic research sample during the period from $14 / 10 / 2017$ to $21 / 10 / 2017$. The exploratory study aimed to:

Determining the length of time to take special measurements for each patient.

Ensure the safety of the devices used in the measurement.

Training assistants on the accuracy of measurements and knowledge of the devices used.

Basic Study:

After confirming the validity of the tools and devices used in the exploratory study through conducting anatomical studies of the cartilage in the basic research sample which is consists from (10) players during the period from $28 / 10 / 2017$ to $4 / 11 / 2017$. The researcher recorded all the measurements if the players in a specific form for each player of the total sample (14) players.

Statistical treatments used in the research:

Statistical processors were used by using (SPSS) program. The following processors were used (Arithmetic average - Mediator 
- Standard deviation - torsion coefficient - lowest value highest value - Pearson correlation coefficient)

Presentation and discussion of the results:

First: Results Presentation:
Results presentation of the first question "what is the anatomical measurements of the size of the neural channel in the research sample?

\section{Table (2)}

The arithmetic average, the lowest and highest value of the anatomical measurements of the size of the neural tube for the sample of the research.

\begin{tabular}{|c|c|c|c|c|c|c|c|}
\hline \multicolumn{2}{|c|}{ Variables } & \multirow{2}{*}{$\begin{array}{c}\begin{array}{c}\text { Unit of } \\
\text { measurement }\end{array} \\
\mathrm{mm} \\
\end{array}$} & \multirow{2}{*}{$\begin{array}{c}\text { The } \\
\text { Arithmetic } \\
\text { Average }\end{array}$} & \multirow{2}{*}{$\begin{array}{c}\text { Mediator } \\
29.400 \\
\end{array}$} & \multirow{2}{*}{$\begin{array}{c}\begin{array}{c}\text { Standard } \\
\text { Deviation }\end{array} \\
2.743 \\
\end{array}$} & \multirow{2}{*}{$\begin{array}{c}\begin{array}{c}\text { Lowest } \\
\text { value }\end{array} \\
26.100 \\
\end{array}$} & \multirow{2}{*}{$\begin{array}{c}\begin{array}{c}\text { Highest } \\
\text { value }\end{array} \\
33.900 \\
\end{array}$} \\
\hline \multirow{5}{*}{$\begin{array}{l}\text { Width of } \\
\text { the neural } \\
\text { tube of the } \\
\text { vertebrae } \\
\text { lumbar }\end{array}$} & $\overline{\mathrm{L} 1}$ & & & & & & \\
\hline & $\mathrm{L} 2$ & $\mathrm{~mm}$ & 29.850 & 29.100 & 2.109 & 28.400 & 33.800 \\
\hline & L3 & $\mathrm{mm}$ & 31.930 & 33.500 & 3.014 & 27.600 & 34.500 \\
\hline & L4 & $\mathrm{mm}$ & 32.900 & 34.800 & 5.383 & 25.500 & 39.100 \\
\hline & L5 & $\mathrm{mm}$ & 38.550 & 39.600 & 3.049 & 34.500 & 41.200 \\
\hline \multirow{4}{*}{$\begin{array}{l}\text { Length of } \\
\text { the neural } \\
\text { tube of the } \\
\text { vertebrae } \\
\text { lumbar }\end{array}$} & L1-L2 & $\mathrm{mm}$ & 13.490 & 13.250 & 2.583 & 9.900 & 16.600 \\
\hline & L2-L3 & $\mathrm{mm}$ & 14.490 & 14.850 & 2.803 & 10.400 & 17.500 \\
\hline & L3-4 & $\mathrm{mm}$ & 11.670 & 12.150 & 2.077 & 8.400 & 13.500 \\
\hline & L4-L5 & $\mathrm{mm}$ & 9.490 & 9.650 & 1.431 & 7.800 & 11.200 \\
\hline
\end{tabular}

It is clear from table (2) that the arithmetic average of the sample in the size of the neural tube and the width of the neural tube of the different lumbar vertebrae ranged between (29.640: 38.550) with the lowest value which ranged between (25.500: 28.400). The highest value ranged between (34.500: 41.200) When the value of the mediator of the length of the neural tube of the different lumbar vertebrae ranged between (9.490: $14.490)$, with the lowest value ranging between $(7,800$ : $10.400)$ and the highest value ranged between (11.200: 17.500).

Results presentation of the second question "What are the anatomical measurements of the cartilage of the lumbar area in the research sample? 
Table (3)

The arithmetic average, the lowest and highest value of the anatomical measurements of the cartilage in the sample of the research. $(\mathbf{N}=10)$

\begin{tabular}{|c|c|c|c|c|c|c|c|}
\hline \multicolumn{2}{|c|}{$\begin{array}{c}\text { Anatomical } \\
\text { Variables } \\
\text { For Cartilage }\end{array}$} & $\begin{array}{c}\text { Unit of } \\
\text { measurement }\end{array}$ & $\begin{array}{c}\text { The } \\
\text { Arithmetic } \\
\text { Average }\end{array}$ & Mediator & $\begin{array}{l}\text { Standard } \\
\text { Deviation }\end{array}$ & $\begin{array}{l}\text { Lowest } \\
\text { value }\end{array}$ & $\begin{array}{c}\text { Highest } \\
\text { value }\end{array}$ \\
\hline \multirow{5}{*}{$\begin{array}{l}\text { Lumbar } \\
\text { cartilage } \\
\text { of the } \\
\text { lumbar } \\
\text { vertebrae }\end{array}$} & L1-L2 & Percentage & 52.500 & 37.150 & 32.386 & 26.800 & 58.200 \\
\hline & L2-L3 & Percentage & 42.690 & 42.250 & 9.274 & 30.800 & 55.900 \\
\hline & L3-L4 & Percentage & 46.650 & 49.200 & 6.121 & 36.600 & 52.500 \\
\hline & L4-L5 & Percentage & 55.140 & 61.200 & 8.141 & 44.300 & 61.600 \\
\hline & L5-S1 & Percentage & 38.660 & 40.100 & 9.771 & 26.700 & 50.500 \\
\hline \multirow{5}{*}{$\begin{array}{l}\text { Height of } \\
\text { the front } \\
\text { cartilage } \\
\text { of the } \\
\text { lumbar } \\
\text { vertebrae }\end{array}$} & L1-L2 & $\mathrm{mm}$ & 9.760 & 9.700 & 1.289 & 8.300 & 11.300 \\
\hline & L2-L3 & $\mathrm{mm}$ & 11.890 & 12.600 & 1.260 & 10.300 & 13.100 \\
\hline & L3-L4 & $\mathrm{mm}$ & 14.010 & 14.350 & 1.048 & 12.100 & 14.800 \\
\hline & L4-L5 & $\mathrm{mm}$ & 16.880 & 16.600 & 1.248 & 15.200 & 18.500 \\
\hline & L5-S1 & $\mathrm{mm}$ & 15.360 & 14.700 & 5.510 & 9.100 & 22.500 \\
\hline \multirow{5}{*}{$\begin{array}{l}\text { Height of } \\
\text { the back } \\
\text { cartilage } \\
\text { of the } \\
\text { lumbar } \\
\text { vertebrae }\end{array}$} & L1-L2 & $\mathrm{mm}$ & 6.670 & 6.750 & 0.709 & 5.500 & 7.600 \\
\hline & L2-L3 & $\mathrm{mm}$ & 7.930 & 7.600 & 1.429 & 6.100 & 9.800 \\
\hline & L3-L4 & $\mathrm{mm}$ & 9.340 & 9.250 & 2.706 & 6.200 & 12.600 \\
\hline & L4-L5 & $\mathrm{mm}$ & 10.550 & 9.300 & 2.105 & 9.200 & 13.600 \\
\hline & L5-S1 & $\mathrm{mm}$ & 6.330 & 5.700 & 1.490 & 5.100 & 8.400 \\
\hline \multirow{5}{*}{$\begin{array}{l}\text { Angle of } \\
\text { the } \\
\text { cartilage } \\
\text { of the } \\
\text { lumbar } \\
\text { vertebrae }\end{array}$} & L1-L2 & Point & 6.260 & 6.150 & 3.436 & 2.900 & 10.100 \\
\hline & L2-L3 & Point & 7.270 & 6.950 & 4.572 & 2.200 & 13.300 \\
\hline & L3-L4 & Point & 6.910 & 6.900 & 4.031 & 2.900 & 11.200 \\
\hline & L4-L5 & Point & 8.460 & 7.900 & 4.054 & 3.500 & 15.100 \\
\hline & L5-S1 & Point & 5.790 & 5.750 & 2.140 & 3.100 & 8.600 \\
\hline \multirow{5}{*}{$\begin{array}{l}\text { Angle } \\
\text { between } \\
\text { lumbar } \\
\text { vertebrae }\end{array}$} & L1 & Point & 12.010 & 12.150 & 1.577 & 9.300 & 13.600 \\
\hline & L2 & Point & 13.380 & 13.700 & 3.187 & 8.200 & 17.600 \\
\hline & L3 & Point & 11.000 & 12.300 & 2.847 & 5.600 & 12.500 \\
\hline & $\mathrm{L} 4$ & Point & 11.850 & 12.000 & 1.539 & 10.100 & 13.400 \\
\hline & L5 & Point & 14.110 & 13.400 & 2.478 & 12.100 & 18.500 \\
\hline \multicolumn{2}{|c|}{$\begin{array}{l}\text { Angle of the lumbar } \\
\text { area }\end{array}$} & Point & 31.950 & 31.950 & 4.711 & 26.800 & 37.100 \\
\hline \multicolumn{2}{|c|}{ Degree of pain } & Point & 5.900 & 6.500 & 1.370 & 0.000 & 7.000 \\
\hline \multicolumn{4}{|c|}{$\begin{array}{l}\text { It is clear from table } \\
\text { (3) that the arithmetic average } \\
\text { of the sample in the anatomical } \\
\text { measurements of the cartilage, }\end{array}$} & $\begin{array}{l}\text { the per } \\
\text { cartilage } \\
\text { vertebrae } \\
\text { (55.140: }\end{array}$ & $\begin{array}{l}\text { entage of } \\
\text { of the } \\
\text { ranged } \\
38.600)\end{array}$ & $\begin{array}{l}\text { Lum } \\
\text { lum } \\
\text { betwe } \\
\text { with }\end{array}$ & \\
\hline
\end{tabular}


lowest value which ranged between (26.700: 44.300). The highest value ranged between (50.500: 61.600) while the value of the mediator of the height of the front cartilage of the lumbar vertebrae ranged between (6.330: 10.550), with the lowest value ranging between (5,100: 9.200) and the highest value ranged between (7.600: 13.600). The value of the mediator of Angle of the cartilage of the lumbar vertebrae ranged between (5.790: 8.460), with the lowest value ranging between $(2,200$ : 3.500 ) and the highest value ranged between (8.600: 15.100). The arithmetic average between the different lumbar vertebrae ranged between (11.00:14.11) with the lowest value ranging from (5,600: 12,100) and the highest value ranged between (12,500:18,500). The arithmetic average of the lumbar angle was (31.95) the lowest value was (25.800) and the highest value (37.100). The average degree of pain (5.900) with the lowest value (5.00) and the highest value (7.00).

Presentation of the results of the third question "Is there a relationship between anatomical measurements of cartilage, neural tube size, and lower back pain?

Table (4)

\section{Relationship between anatomical measurements of neural tube} size and sense of pain degree. $(\mathrm{N}=10)$

\begin{tabular}{l|c|c|c}
\hline \hline \multicolumn{2}{c|}{$\begin{array}{c}\text { Anatomical Variables of the } \\
\text { Neural tube }\end{array}$} & $\begin{array}{c}\text { Measuring } \\
\text { Unit }\end{array}$ & $\begin{array}{c}\text { Sense of Pain } \\
\text { Degree }\end{array}$ \\
\hline \hline \multirow{3}{*}{$\begin{array}{l}\text { Width of the neural } \\
\text { tube of the lumbar } \\
\text { vertebrae }\end{array}$} & $\mathrm{L} 2$ & $\mathrm{~mm}$ & $* .830$ \\
\cline { 2 - 4 } & $\mathrm{L} 3$ & $\mathrm{~mm}$ & $* .835$ \\
\cline { 2 - 4 } & $\mathrm{L} 4$ & $\mathrm{~mm}$ & $* .964$ \\
\cline { 2 - 4 } & $\mathrm{L} 5$ & $\mathrm{~mm}$ & $* .955$ \\
\hline \multirow{2}{*}{$\begin{array}{l}\text { Length of the neural } \\
\text { tube of the lumbar } \\
\text { vertebrae }\end{array}$} & L1-L2 & $\mathrm{mm}$ & $* .653$ \\
\cline { 2 - 4 } & L2-L3 & $\mathrm{mm}$ & $* .811$ \\
\cline { 2 - 4 } & L3-4 & $\mathrm{mm}$ & $* .750$ \\
\hline \hline \\
\hline \multirow{4}{*}{ Assiut Journal For Sport Science Arts } \\
\hline
\end{tabular}


It is clear from Table (4) that there is a significant correlation between the search variables, the size of the neural tube and the degree of pain. The correlation coefficient of the width of the neural tube of the lumbar vertebrae and the sense of pain degree ranged between (0.830) to (0.993). The correlation coefficient of

\section{Table (5)}

\begin{tabular}{c}
$\begin{array}{c}\text { Relationship between anatomical measurements of cartilage and } \\
\text { sense of pain degree. }(\mathrm{N}=10)\end{array}$ \\
\hline \hline
\end{tabular}

$\begin{array}{r}\begin{array}{r}\text { Relationship between anatomical measurement } \\ \text { sense of pain degree. }(\mathbf{N}=10)\end{array} \\ \hline \hline\end{array}$

\begin{tabular}{|c|c|c|c|}
\hline \multicolumn{2}{|l|}{ Variables } & \multirow{2}{*}{$\begin{array}{c}\begin{array}{c}\text { Measuring } \\
\text { Unit }\end{array} \\
\text { Percentage } \\
\end{array}$} & \multirow{2}{*}{$\begin{array}{c}\begin{array}{c}\text { Sense of } \\
\text { Pain Degree }\end{array} \\
*_{-.998}\end{array}$} \\
\hline \multirow{5}{*}{$\begin{array}{l}\text { Lumbar cartilage of the } \\
\text { lumbar } \\
\text { vertebrae }\end{array}$} & L1-L2 & & \\
\hline & L2-L3 & Percentage & $*_{-} .853$ \\
\hline & L3-L4 & Percentage & $*_{-.775}$ \\
\hline & L4-L5 & Percentage & *-.941 \\
\hline & L5-S1 & Percentage & $*_{-.890}$ \\
\hline \multirow{5}{*}{$\begin{array}{l}\text { Height of the front } \\
\text { cartilage of the lumbar } \\
\text { vertebrae }\end{array}$} & L1-L2 & $\mathrm{mm}$ & *-.939 \\
\hline & L2-L3 & $\mathrm{mm}$ & $*_{-.776}$ \\
\hline & L3-L4 & $\mathrm{mm}$ & $*_{-.934}$ \\
\hline & L4-L5 & $\mathrm{mm}$ & $*-.715$ \\
\hline & L5-S1 & $\mathrm{mm}$ & $*_{-.911}$ \\
\hline \multirow{5}{*}{$\begin{array}{l}\text { Height of the back } \\
\text { cartilage of the lumbar } \\
\text { vertebrae }\end{array}$} & L1-L2 & $\mathrm{mm}$ & *..795 \\
\hline & L2-L3 & $\mathrm{mm}$ & $*_{-.951}$ \\
\hline & L3-L4 & $\mathrm{mm}$ & $*_{-} .937$ \\
\hline & L4-L5 & $\mathrm{mm}$ & $*_{-.953}$ \\
\hline & L5-S1 & $\mathrm{mm}$ & $*_{-} .891$ \\
\hline
\end{tabular}

the length of the neural tube of the lumbar vertebrae and the sense of pain degree ranged between $(0.653)$ to $(0.868)$. All values are greater than their tabular value at the level of significance (0.05), indicating a significant correlation between the search variables, the size of the neural tube and the sense of pain degree. 
Follow Table (5)

Relationship between anatomical measurements of cartilage and sense of pain degree. $(\mathrm{N}=10)$

\begin{tabular}{|c|c|c|c|}
\hline \multicolumn{2}{|l|}{ Variables } & \multirow{2}{*}{$\begin{array}{c}\begin{array}{c}\text { Measuring } \\
\text { Unit }\end{array} \\
\text { Point }\end{array}$} & \multirow{2}{*}{$\begin{array}{c}\begin{array}{c}\text { Sense of } \\
\text { Pain Degree }\end{array} \\
*_{-.832} \\
\end{array}$} \\
\hline \multirow{5}{*}{$\begin{array}{l}\text { Angle of the cartilage of } \\
\text { the lumbar } \\
\text { vertebrae }\end{array}$} & L1-L2 & & \\
\hline & L2-L3 & Point & $*_{-.995}$ \\
\hline & L3-L4 & Point & $*_{-.890}$ \\
\hline & L4-L5 & Point & $*_{-.924}$ \\
\hline & L5-S1 & Point & $*_{-} .861$ \\
\hline \multirow{5}{*}{$\begin{array}{l}\text { Angle between lumbar } \\
\text { vertebrae }\end{array}$} & L1 & Point & $*$ *.756 \\
\hline & L2 & Point & $*_{-} .803$ \\
\hline & L3 & Point & $*_{-.863}$ \\
\hline & L4 & Point & $*_{-.886}$ \\
\hline & L5 & Point & $*_{-} .843$ \\
\hline Angle of the lumbar area & & angle & $*_{-.864}$ \\
\hline
\end{tabular}

Table (5) shows that there is an inverse correlation between the research variables, the anatomical measurements of the cartilage and the degree of pain sensation. The correlation coefficient of the lumbar cartilage of the lumbar vertebrae and the sense of pain degree ranged between $(-0.775)$ to $(-0.998)$. The correlation coefficient of the angle of the cartilage of the lumbar vertebrae and the sense of pain degree ranged between $(-0.85)$ to $(-0.995)$. There was also a significant correlation between the research variables, the anatomical measurements of the cartilage and the sense of pain degree, as the correlation coefficient of height of the front cartilage of the lumbar vertebraeand the sense of pain degree ranged between $(-0.715)$ to $(-0.939)$.

Also, the correlation coefficient of height of the back cartilage of the lumbar vertebrae and the sense of pain degree ranged between $(-0.891)$ to $(-0.953)$. The 
correlation coefficient of angle between lumbar vertebrae and the sense of pain degree ranged between $(-0.756)$ to $(-0.886)$ $(-0.864)$, while the correlation coefficient of angle of the lumbar area and the sense of pain degree was (-0.864). All values are greater than their tabular value at the level of significance (0.05), indicating a significant correlation between the variables of the anatomical measurements of the cartilage and the degree of sensation of pain.

\section{Second: Discussion of the Results:}

Based on the above results and in light of the research problem and to achieve its goals and questions, the researcher reviews the results and discusses them. Table (1) shows the homogeneity of the research sample in variables of height, weight, age and physical tests.

Discussion of the results of statistical indications on the validity of the first question anatomical measurements of the size of the neural tube in the research sample.

By revising the results of Table 2, It is clear from table (2) that the arithmetic average of the sample in the size of the neural tube and the width of the neural tube of the different lumbar vertebrae ranged between (29.640: 38.550). The value of the mediator of the length of the neural tube of the different lumbar vertebrae ranged between $(9.490$ : 14.490).

This is consistent with the study of Mohamed Adel Rushdie (1997) that sports activity leads to increasing muscle strength, but some sports activities characterized by a specific muscle work in the lower back and for long periods will affect the individual and cause pain which may be perialgia in most of the time, unless the player and coach pay attention to it and work to compensate for this work to find the balance of muscle, such as the intense pressure of gymnasts on the lower back when performing some movements and sports acts. (11: 34)

Mohammed Qadri Bakri and Siham Elsayed AlGhamri (2005) note that the lumbar region represents weak points and problems of mobility for athletes and nonathletes. Due to the vitality of these areas, as it exposes to heavy weight, natural flections 
and the occurrence of motor work to it more than the other areas, it exhibits to many problems and injuries to athletes and others during the exercise and sports activities or to some other jobs, or wrong sit down while writing or misuse of modern technological devices.

Faraj Abdul Hamid Tawfiq (2005) pointed out that the physical exercises increase the flexibility of the joint, thus increase the motor range of the joint, increase the nutrition of the bones to grow properly and increase the elasticity of the muscles working on the joints (25: 9).

As recommended by Magdy Mahmoud and Cook Abdul Basit Siddiq Abdul Jawad (2013) that the muscle strength and flexibility of the vertebral column must be developed through training because of its positive impact on pain relief and muscle efficiency recovery (28:10).

The researcher

concluded that the narrowing of the neural tube results from the mechanical pressure on the lumbar area.

Discussion of the results of statistical indications on the validity of the second question "Anatomical measurements of cartilage of the lumbar area in the research sample".

It is clear from table (3) that the arithmetic average of the sample in the anatomical measurements of the cartilage, the percentage of Lumbar cartilage of the lumbar vertebrae ranged between (55.140: 38.600) with the lowest value which ranged between (26.700: 44.300). The highest value ranged between (50.500: 61.600) while the value of the mediator of the height of the front cartilage of the lumbar vertebrae ranged between (6.330: 10.550), with the lowest value ranging between (5,100: 9.200) and the highest value ranged between (7.600: 13.600). The value of the mediator of Angle of the cartilage of the lumbar vertebrae ranged between (5.790: 8.460), with the lowest value ranging between $(2,200$ : $3.500)$ and the highest value ranged between (8.600: 15.100). The arithmetic average between the different lumbar vertebrae ranged between (11.00:14.11) with the lowest value ranging from $(5,600: 12,100)$ and the highest value ranged between $(12,500$ :18,500). The arithmetic average of the lumbar angle was (31.95) the lowest value was (25.800) And the highest 
value (37.100). The average degree of pain (5.900) with the lowest value (5.00) and the highest value (7.00).

This is confirmed by Baranto et all (2009) that there is a decrease in the height of cartilage in $(90 \%)$ of athletes, especially in weightlifting players and then gymnasts in the dorsal and lumbar areas resulting from the practice of sports. (68:21).

White and Malone study (1999) also suggests that vertebral column cartilage also reduces in the total length of the vertebral column between cartilage height before running and after running (67:30).

In this regard, it is clear from this table that the height of the front and back cartilage in the weight lifting sport is lower. This is confirmed by Plastanga et al. (1998). A cartilage looks like a disc separates between the vertebrae. These discs is $25 \%$ of the length of the vertebral column in adults and about $40 \%$ in children where there are 24 cartilage in the vertebral column between the vertebrae (6) in the neck area, (12) in the chest area, (5) in the abdominal area, one between the fifth lumbar and the primary deficit. The cartilage are responsible for the presence of curvature in the vertebral column to help in easing its movement in all directions and increase the density of the thickness of the cartilage as we head down, starting from the cervical vertebrae to the lumbar vertebrae.

The average thickness of the cartilage in the cervical vertebrae $(5 \mathrm{~mm})$, in the vertebrae thoracales (7 $\mathrm{mm}$ ), and in the lumbar vertebrae is $10 \mathrm{~mm}$. The highest cartilage found between the second and third cervical vertebrae, and the lowest cartilage disc located in the thoracic area.

When the pressure reaches about 100 kilopascal, the cartilage disc loses $8 \%$ of the fluid in the nucleus, $11 \%$ of the watery mix of the fibroblast, especially the back. When the pressure increases to 200 kilopascal for 24 hours. The concentration of potassium increased (20) times more than the sodium within the cartilage disc, which leads to a change in the anatomical composition. There may be a likelihood of infection (634: 27).

Baranto et al. (2009) agree that the anatomical changes of the vertebral column showed a decrease in cartilage height in $(90 \%)$ of the athletes sample and their 
ranking was in the forefront of the weightlifting players then wrestlers and gymnasts then non-practitioners of the sport activity (67:21).

The researcher attributed to the need to perform sports exercises based on the separation of the articular surfaces as well as the lengthening of muscles and the mobility of the joints of the spine to reduce the pressure on the disk cartilage from normal position and reduce pressure on nerve roots and nerve endings of the lumbar area of the vertebral column.

Montasser Ibrahim

Tarfa (2004) also mentions that the vertebral column is considered a joint which is affected by health problems, and the lumbar rea is one of the most affected areas because of sports activities or situations acquired through the activities of daily life (18: 145-144).

Discussion of the results of statistical indications on the validity of the third question "the relationship between the size of the neural tube and anatomical measurements of cartilage and lower back pain.

It is clear from Table (4) that there is a significant correlation between the research variables, the size of the neural tube and the degree of feeling of pain. All values are greater than their tabular value at the level of significance (0.05).

As shown in Table (5), there is a significant correlation between the research variables, the anatomical measurements of cartilage and the degree of sensation of pain, the anatomical measurements of the cartilage and the degree of sensation of pain and all values greater than their tabular value at the level of significance (0.05).

This was agreed with Hassan Mohammed AlNawasirah (1984), quoting David Davied, that the area of the back represents the most important areas responsible for the efficiency of movement and activity in individuals because it has the vertebral column, which is the central axis of the human body and the common factor active in all activities and movements, thus it is the most vulnerable areas for diseases and stress, especially in the most areas of movement, the area of lumbar and cervical vertebrae, where cartilage discs are thicker in the chest area, and this property increases the ability of these 
areas to move, whether positive or negative movements (7: 21-6).

Also Hayat Ayad Rofael and Safa El-Din AlKharbotli (1995) confirm that the muscles connected to the spine have a significant effect on the increase or decrease of the spine curvature. If these muscles weaken, the balance will blemish and a change will happen in the shape of the natural curves accordingly, and may cause spinal pain, especially for athletes when exercising incorrectly.

Sports training needs to standardized stages. If these stages these stages are neglected to elevate the athlete to a high level, may be exposed to problems of the spine such as increased lumbar concubine, shortness of neural tube, and pelvic tilt in front, especially in weightlifting players and may lead to pain in the lumbar area which happens because of the repetitive performance of the moment bumping bumps with each other (8: 73).

\section{Research findings:}

In light of the objectives and procedures of the research and the results of the statistical treatments used and after presentation and discussion, the researcher reached the following

\section{conclusions:}

Anatomical measurements of the neural tube in the lumbar region vary according to the activity of the athlete.

Weight gain in loading and mechanical pressure on the lumbar region of the spine leads to lower anatomical measurements of the cartilage.

The size of the neural tube of the lumbar area varies according to the quality of the skill and the quality of the exercise.

There is a positive relationship in the presentation of the neural tube to the lumbar area and the degree of pain sensation in the research sample.

Record variable of the width of the neural tube of the lumbar vertebrae in the spine of the study sample group was lower than the normal rates in the research sample (weight lifting more than wrestling)

Anatomical changes in the thickness of the cartilage of the lumbar vertebrae vary depending on the shape and type of performance the practitioner differs from the weightlifting players from the wrestlers.

There was a significant decrease in the variable cartilage height between the third and fourth lumbar 
puncture in the research sample due to pressure on the lumbar region.

\section{Research recommendations:}

In the light of the results of the research and based on the conclusions reached in light of the research objectives, the researcher makes the following recommendations:

The importance of attention to the anatomical changes of the spine in general and the lumbar region in particular for athletes sports activities that rely on the mechanical load on the lumbar region.

Development and evaluation of the muscles of the lumbar region in the initial periods of training for different stages of age because this region represents the seat belt, which shows a cycle in the protection of the spine.

Warm up the good work and work exercises prolongation and flexibility before the implementation of the training module.

Strengthen abdominal muscles by doing exercises for this area at least (3) times a week.
To avoid randomization in diagnosis and to find out the real cause of feeling pain by doing a CT scan to determine the type and degree of angle of injury to be able to choose appropriate treatments and avoid the incidence of infection.

Conducting continuous follow-up of the vertebrae and cartilage with necessary radiology at the beginning and end of the season to identify the changes that occur to cartilage discs and form the neural tube, which helps guide the training process.

The researcher is recommended to make more measurements on the rest of the body to identify

On anatomical changes under the influence of regular training practice.

Long-term follow-up studies to follow closely the anatomical changes that occur in the lumbar region of each sport.

Taking into account the exercise of compensatory muscles working on the back to avoid pain. 